\title{
Notas sobre as fontes de formação de John Dewey com base no próprio autor
}

\section{Notes on the sources of John Dewey's education based on the author himself}

\author{
Mirian Jorge Warde
}

\begin{abstract}
RESUMO
Este texto trata das fontes da Filosofia e da Psicologia de John Dewey segundo o próprio Dewey. $\mathrm{O}$ destaque à Filosofia e à Psicologia deweyanas decorre do entendimento que, além de serem essas as duas disciplinas para as quais Dewey realizou seus maiores investimentos intelectuais, elas estão intricadamente vinculadas em sua obra. Com esse recurso, pretende-se examinar os procedimentos adotados por Dewey para relevar ou obscurecer momentos do seu processo de maturação intelectual. O período abarcado neste texto é o de sua formação na Universidade de Vermont (1875-1879) e na Johns Hopkins (1882-1883), onde obteve o seu título de doutor, em 1884, que lhe permitiu dar início à carreira profissional. São duas as questões de fundo abordadas: de um lado, a insistência de Dewey em negar suas pretensões teológicas, bem como os seus esforços em apresentar seus problemas religiosos em moldes filosóficos; de outro, a tendência de Dewey, que se revela desde os seus primeiros ensaios publicados, de usar e dispensar com muita rapidez e com certa simplificação ou esquematização as suas fontes quer pessoais quer bibliográficas. De Dewey, foi utilizado como ponto de partida o texto "From Absolutism to Experimentalism", de 1930, que se constitui numa boa autobiografia intelectual. Como bibliografia de apoio foram utilizados trabalhos de biógrafos de J. Dewey e de outros estudiosos de sua obra, destacadamente aqueles que se dedicaram a reconstituir a sua trajetória intelectual.
\end{abstract}

Palavras-chave: John Dewey; religião; Filosofia; Psicologia; hegelianismo.

${ }^{1}$ Doutora em Filosofia da Educação pela Pontifícia Universidade Católica de São Paulo (PUC/ SP). Professora Visitante do Programa de Pós-Graduação em Educação da Universidade Federal de São Paulo (UNIFESP), campus Guarulhos, Brasil. Pesquisador Sênior do CNPq - Conselho Nacional de Desenvolvimento Científico e Tecnológico, Brasil.E-mail: mjwarde@uol.com.br 


\begin{abstract}
This paper addresses the sources of philosophy and psychology of John Dewey, according to Dewey himself. The emphasis on Deweyan Philosophy and Psychology stems from the understanding that, apart from the fact that these two disciplines are those in which Dewey made his greatest intellectual investments, they are intricately linked to one another in his work. In this article, we intend to examine the processes used by Dewey to reveal or obscure moments of his intellectual maturation process. The period covered in this text is from Dewey's education at the University of Vermont (18751879) through his time at Johns Hopkins (1882-1883) where he obtained his doctoral degree in 1884 and which allowed him to begin his academic career. There are two main issues addressed: on one hand, Dewey's insistence on denying his theological inclinations, and his efforts to present his religious problems in philosophical terms; and on the other hand, Dewey's tendency - revealed from his earliest published essays - to use and dispose of both his personal and bibliography resources, very quickly and with some simplification. The point of departure for this essay was Dewey's text "From Absolutism to Experimentalism", 1930, which is a good intellectual autobiography. Additional bibliographic references include the works of J. Dewey and other scholars who dedicated themselves to reconstructing Deweyan intellectual career.
\end{abstract}

Keywords: John Dewey; religion; Philosophy; Psychology; hegelianism.

\title{
Introdução
}

Este artigo trata das fontes da Filosofia e da Psicologia de John Dewey segundo sua própria exposição. O destaque à Filosofia e à Psicologia deweyana decorre do entendimento de que além de serem essas as duas disciplinas nas quais Dewey realizou seus maiores investimentos intelectuais, elas se apresentam intricadamente associadas em seus trabalhos de educação.

Quanto à utilização do próprio Dewey como referência às fontes intelectuais, que teriam contribuído diretamente para o arranjo de suas ideias filosóficas e psicológicas, trata-se de iniciativa de que visa trazer a lume, de um lado, referências pouco utilizadas pelos seus estudiosos e biógrafos (dentre outros, DYKHUIZEN, 1973; COUGHLAN, 1975); de outro, constitui uma estratégia de tornar o estilo deweyano de lidar com o processo de formação intelectual no caso, o seu próprio processo - mais familiar aos que mantêm interesse por suas ideias pedagógicas. 
Com esse recurso, pretende-se examinar os procedimentos adotados por Dewey para relevar ou obscurecer momentos do seu processo de maturação intelectual, admitindo-se que os estímulos de determinado autor a outro não se dão apenas pela via da concordância, e muito menos da adesão passiva. Há muitos exemplos na história e na sociologia do conhecimento ocidental nos quais as marcas do pensamento negado são mais estruturais e estruturantes do que daquele explicitamente afirmado ${ }^{2}$.

Considera-se essa operação especialmente relevante em função do estilo discursivo adotado por Dewey em que os autores e as obras mencionados são escassa ou genericamente referenciados. Embora o estilo compareça desde as suas primeiras publicações, por certo ganha relevo com o avanço dos controles acadêmicos, e à medida que crescem as exigências editoriais e os rigores das citações e referências completas.

John Dewey nunca foi dado a minuciosas ou regulares citações e referências a autores e obras. Entretanto, não cabe dispensá-los dessas exigências em nome de que não eram usuais à sua época. Seus contemporâneos acadêmicos - destacadamente os da Psicologia - já se utilizavam fartamente desse recurso.

\section{O período de Vermont}

Em texto publicado em 1930, From Absolutism to Experimentalism, John Dewey faz uma breve retrospectiva de sua trajetória intelectual visando, particularmente, o despertar do seu interesse pela Filosofia e pela Psicologia.

O primeiro nome citado é o de Thomas Huxley (1825-1895) cujo livro de fisiologia, Elements of Physiology, foi indicado em um curso "eletivo" durante a graduação na Universidade de Vermont (1875-1879). O curso despertou o que "em retrospectiva" Dewey chama de "o seu gosto filosófico". Desse estudo, ele teria extraído

[...] um sentido de interdependência e de unidade inter-relacionada, que deu forma aos impulsos intelectuais que tinham sido até então incipientes, e criou uma espécie de tipo ou modelo de uma visão das coisas à qual a matéria, em qualquer campo, devia obedecer. Subconscientemente, pelo se afirmou.

${ }^{2}$ A presença de Hegel em Marx e de Croce em Gramsci são dois exemplos do que acima 
menos, fui levado a desejar um mundo e uma vida que tivesse as mesmas propriedades do organismo humano tal como na imagem derivada da abordagem de Huxley [...]. Eu dato daquele momento o despertar de um interesse filosófico especial (DEWEY, 1930, p. 147-148).

A época, Dewey tinha dado início a leituras mais regulares e sistemáticas de obras cientificamente orientadas. Na fase final do seu curso, leu e fez as anotações nos dois volumes de Principles of Psychology de Herbert Spencer (1820-1903); anos depois, Dewey e se refere também ao A System of Synthetic Philosophy de Spencer (DEWEY, 1904). Além de outros livros de Fisiologia e disciplinas afins, enveredou na leitura de Auguste Comte (1798-1857) que, ao lado de Spencer e Huxley, conduziu seus interesses científicos na direção da Filosofia e dos estudos sociais (KUKLICK, 1985).

A orientação de seus interesses intelectuais para a Filosofia não deixou Dewey solitário na Universidade de Vermont. Fundada em 1791, o quinto mais antigo College da Nova Inglaterra, era considerado um dos melhores centros de formação filosófica quando nele Dewey ingressou. Para alguns historiadores, como Jay (2002), o currículo de Vermont igualava-se ou, em certos aspectos, ultrapassava os equivalentes de quatro colleges criados anteriormente na Nova Inglaterra, todos destinados somente a rapazes: Harvard, Yale, Brown e Dartmouth (KUKLICK, 1977, 1985; MARSDEN, LONGFIELD, 1992). Para a Universidade de Vermont destinavam-se os filhos da elite de Burlington: educados, livres-pensadores e protestantes congregacionais ${ }^{3}$.

A orientação filosófica institucional que prevalecia na Universidade de Vermont vinha dos anos vinte quando o Reverendo James Marsh assumira a presidência da Universidade e buscara convertê-la em um grande centro norte-americano de estudo de Filosofia.

De James Marsh (1794-1842), dos mais antigos professores da Universidade de Vermont, Dewey diz, no texto de 1930, ter sido uma das primeiras pessoas nos Estados Unidos a se aventurar no "speculative and dubiously orthodox seas of German thinking", isto é, Kant, Schelling e Hegel, e que o teria feito basicamente por meio de Samuel T. Coleridge (1772-1834). Apesar de ter-se mantido na tendência um tanto óbvia de racionalizar o corpo das doutrinas teológicas cristãs, Marsh teria provocado um alvoroço no edifício eclesiástico;

${ }^{3}$ Matthew H. Buckham, presidente da Universidade de Vermont quando nela John Dewey realizou seus estudos, era primo de Lucina Dewey, mãe de John Dewey. O ramo materno da família era bastante bem educado e aberto ao congregacionalismo liberal. 
alimentara, particularmente, uma controvérsia com fortes impactos na história do pensamento norte-americano.

Ainda se referindo à orientação institucionalizada, Dewey comenta que, embora a Universidade continuasse orgulhosa do seu trabalho pioneiro, e de sua atmosfera ser naquela época teologicamente "liberal" - do tipo congregacional - o ensino de Filosofia havia se tornado mais restrito, mais influenciado pela ainda dominante "Scotch school"4 (DEWEY, 1930, p. 148).

A referência um tanto reticente a James Marsh, no escrito de 1930, não faz justiça à sua forte presença na formação de Dewey, admitida pelo próprio Dewey em outras circunstâncias. Afirma em James Marsh and American Philosophy (1941) que Marsh teria marcado suas especulações uma vez que leu Kant por meio da física de Aristóteles e de Newton para chegar à conclusão que espaço e tempo não seriam meras formas mentais, como queria Kant, mas "formas externas e reais das coisas da natureza" ". Para Marsh o real percebido poderia ser distinguido dos atos da mente, e essa "psicologia racional" teria servido de base, ainda que sem plena consciência, para Dewey erigir uma psicologia naturalista ${ }^{6}$.

Segundo Schneider (1950), antigo aluno de Dewey em Columbia, as primeiras manifestações de entusiasmo por uma forma mais elaborada de espiritualismo - em reação ao calvinismo - teriam surgido entre os eclesiásticos ilustrados que, apesar de adeptos de uma teologia crítica, acreditavam na possibilidade de justificar filosoficamente uma fé que tivesse poder na prática. Ao Reverendo James Marsh teriam cabido as primeiras iniciativas nessa direção por meio da publicação da obra de Coleridge, Aids to Reflection. Utilizando-se da reflexão filosófica como uma nova forma de religião e fazendo dessa reflexão o seu método de ensino, Marsh criou uma tradição acadêmica na Universidade de Vermont. Ainda sobre Marsh, diz Schneider (1950, p. 265): “a filosofia de vida como um processo criador se converteu no interesse dominante da própria exposição de Marsh do transcendentalismo" (SCHNEIDER, 1950, p. 265).

${ }^{4}$ Dewey se refere ao realismo escocês que prevaleceu nos Estados Unidos até a primeira metade do séc. XIX, destacadamente no Princeton Theological Seminary, originalmente denominado de College of New Jersey. Dentre os muitos nomes a serem lembrados, destaque-se aqui o da "escola escocesa": Thomas Reid (1710-96), Essays on the Intellectual Powers of Man; Dugald Stewart (1753-1828), Elements of the Philosophy of the Human Mind, e William Hamilton (Sir, 1788-1856), Lectures on Metaphysics and Logic.

${ }^{5} \mathrm{O}$ texto James Marsh and American Philosophy foi publicado pela primeira vez em 1941 com base em uma lecture que ele apresentou na University of Vermont, em 1929, em comemoração ao centenário da publicação da Introdução ao Aids to Reflection de Coleridge.

${ }^{6}$ A respeito, diz Menand (2001, p. 149): “A filosofia de Burlington era transcendentalista, mas não emersoniana. Quando Marsh falava de ‘intuição' ele não queria dizer 'sentimento'. O que dizia era quase o oposto de sentimento: queria significar rigorosamente introspecção e análise”. 
Para Kuklick (1985), os transcendentalistas de Burlington sacrificaram a influência nos colleges e seminários, e no pensamento formal, para ser a vanguarda da nova cultura erudita. Em contrapartida, Marsh ganhou uma limitada batalha acadêmica ao institucionalizar suas ideias em Vermont, mas fracassou na grande batalha:

Ele pretendia ser um filósofo e não um teólogo, e prover o calvinismo com as premissas de um credo experimental. Mas ao forçar a "cristandade coleridgeana", Marsh subestimou a oposição ao pensamento alemão nos anos de 1830 (KUKLICK, 1985, p. 159).

Dewey leu, em classe, a edição de Marsh do Aids to Reflection de Coleridge e aderiu entusiasticamente à síntese entre Filosofia e fé que lhe produzia o efeito desejado de fazer o cristianismo parecer compatível com o pensamento moderno, com a ciência e com o evolucionismo darwiniano (MENAND, 2001). Anos depois, revelaria ainda um senso de currículo bastante afeito ao que Marsh adotara para a reforma institucional enquanto esteve na presidência da Universidade de Vermont. Nesse aspecto, saiu-se vitorioso.

Com base em "coleridgeanos" princípios, Marsh integrou o currículo da Universidade concebendo-o como um todo, tal como o conhecimento é um todo integrado que dá coerência ao trabalho em cada departamento; instituiu o sistema de "cursos eletivos" - o primeiro nos Estados Unidos -, admitiu estudantes em tempo parcial, desencorajou os exames formais e culminou o currículo com um "senior-year" curso de Filosofia planejado para introduzir os estudantes na unidade de todo o conhecimento (MENAND, 2001) 7 .

Avançando no From Absolutism to Experimentalism, Henry A. P. Torrey é o nome que aprece em seguida. Professor de Dewey e seu primeiro mentor, Torrey havia estudado no Union Theological Seminary de Nova York, embora tenha trocado o púlpito pelo magistério universitário.

Em termos de orientação filosófica, Henry Torrey seguia a tradição de Vermont, isto é, de $\mathrm{Marsh}^{8}$, mas em aula expunha, com moderação, tanto o realismo escocês quanto a doutrina kantiana. A seu respeito, Dewey diz ter

${ }^{7}$ Sobre a reforma de Marsh, diz Kuklick (1985, p. 159), após destacar seu sentido integrado e orgânico: "Além do mais, o currículo refletia o avanço do conhecimento e calibrava esse avanço com a maturação dos estudantes. Conseqüentemente, as [disciplinas] eletivas eram permitidas, o currículo era minimamente orientado às necessidades práticas, e o trabalho de ano a ano era flexível".

${ }^{8} \mathrm{H}$. Torrey utilizava The Remains of the Ver. James Marsh como livro-texto. 
sido um homem de mente culta e genuinamente sensível, com marcante gosto e interesse estético que teria encontrado um ambiente apropriado para florescer na Nova Inglaterra, não fosse sua timidez congênita. De qualquer modo, Torrey expressava genuíno ("not perfunctory") interesse pela Filosofia; além de excelente professor com quem Dewey manteria duplo débito por ter definitivamente mudado o rumo dos seus pensamentos na direção do estudo da Filosofia como um projeto de vida, e por ter generosamente lhe dedicado um ano de orientação particular para leitura dos clássicos da história da Filosofia e para aprender a ler a Filosofia alemã (DEWEY, 1930).

Fechando o período de Vermont, Dewey comenta em From Absolutism... a presença quase absoluta de clérigos na docência de Filosofia, reservada quase exclusivamente a homens. Exigia-se formação religiosa ou teológica para se ensinar a matéria. E por razões que não sabe explicar, reitera a existência à época de "uma firme aliança entre religião e a causa da "intuição"”. Havia uma aura sacrossanta a envolver a ideia de intuição, e o único problema vital estava entre o intuicionismo e o empirismo sensorial que prestava contas da realidade de todos os objetos superiores.

Sobre a sua relação com esse "quase esquecido debate", diz Dewey (1930, p. 149), essa história

[...] é provavelmente um fator do desenvolvimento em mim de certo ceticismo sobre a profundidade e a amplitude dos problemas puramente contemporâneos; é provável que muitos daqueles que parecem altamente importantes hoje, serão relegados ao status de locais ou provinciais. Isso auxilia a gerar um senso de valor da história da Filosofia; algumas das alegações feitas em favor como uma única avenida de aproximação aos estudos de problemas filosóficos parecem inadequados e danosos. Mas seu valor em conferir perspectiva e um senso de proporção em relação aos problemas contemporâneos imediatos dificilmente podem ser superestimados.

A afirmação da forte presença do intuicionismo ou do realismo da escola escocesa de Filosofia nos meios religiosos e teológicos serve a Dewey para se desembaraçar de qualquer interesse teológico desde a época da sua formação.

Eu não menciono essa fase teológica ou intuitiva porque ela não deixou qualquer influência sobre meu próprio desenvolvimento, exceto negati- 
vamente. Eu aprendi a terminologia de uma filosofia intuitiva, mas eu não aprofundei, e de nenhum modo ela satisfez o que eu estava confusamente buscando. Eu fui criado em uma atmosfera evangélica convencional, do tipo mais "liberal"; e os conflitos que cresceram depois entre aceitação daquela fé e a dispensa dos credos institucionais e tradicionais vieram de experiências pessoais não de efeitos do ensino filosófico. Em outras palavras, não foi desse ponto de vista que a Filosofia me atraiu ou me influenciou - embora eu não esteja certo que o Analogy de Butler, com sua lógica fria e sua análise aguda, não tenha sido, na contramão, um fator de desenvolvimento do "ceticismo" (DEWEY, 1930, p. 149-150).

Por certo que as suas ações - tais como organizar a Young People's Society da First Congregational Church de Burlington (1881); conduzir as aulas de Bíblia de uma turma da Students' Christian Association (1884) - e suas preocupações intelectuais registradas em escritos menos relevantes, tais como The Obligation to Knowledge of God (1884) ou mais decisivos como Soul and Body (1886), patenteiam inquietações religiosas ou teológicas não apenas suas, mas de quase todos os seus contemporâneos, ainda que se apresentem sob outras roupagens (MARSDEN, 1970, 1990).

No fechamento do seu texto de 1930, Dewey retorna à questão de a religião nunca ter se constituído um problema filosófico, uma vez que sempre lhe pareceu mais relevante a experiência religiosa do que a adoção de uma religião em particular (DEWEY, 1930). Aqui, resumidamente, repõe a lógica que perseguiu desde seus anos de formação: a lógica da experiência de vida que permite expandir o âmbito religioso para todas as esferas da vida não religiosa. Para Dewey, não se tratava, portanto, de encolher as esferas não religiosas para contê-las toda na religião; bem ao contrário, tratava-se de expandir a vida religiosa de sorte a incorporar toda a diversidade da vida vivida.

Com isso, é claro o diálogo mantido por Dewey com os congregacionalistas progressivistas que aceitaram combinar Hegel com Darwin de sorte a elidir os dualismos do calvinismo: Deus e homem; natural e espiritual. Sobre esse caminho deweyano diz Kuklick (1985, p. 232-233):

Esses temas teológicos aparecem em Dewey sob uma aparência filosófica. Os teólogos liberais estavam conscientes da vaquidade de suas idéias vindas da perspectiva da especulação religiosa tradicional. Dewey pretendeu prover a Nova Teologia de um fundamento técnico mais adequado. Aqui ele seguiu os passos do seu mentor Morris, cujo Philosophy and Cristianity apareceu em 1883. Dewey também interpretou Green [...]. Dewey tinha uma "profunda simpatia" pela visão de que a base de qual- 
quer apologética cristã tinha que ser a filosofia da religião. O movimento espiritual trazendo homem e natureza "para a unidade acabada e ampla" deve, escreveu Dewey, deve ganhar expressão filosófica.

\section{De Burlington a Baltimore; da University of Vermont a Johns Hopkins University}

Foi no período de tutoria de Torrey que Dewey criou segurança suficiente para enviar para publicação seus dois primeiros artigos - The Metaphysical Assumptions of Materialism e The Panteism of Spinoza - nos quais defende a Filosofia de Burlington, refutando o materialismo e buscando demonstrar a compatibilidade entre ciência e religião, evolucionismo e teologia. Utilizou-se de um caminho curioso para não defender o cristianismo, mas sim atacar as pressuposições do materialismo.

Os artigos foram publicados pelo Journal of Speculative Philosophy em 1882, mesmo ano que Dewey começa os estudos na Johns Hopkins University. Sobre esses artigos, diz Dewey (1930, p. 150) em From Absolutism...

Durante os anos posteriores à graduação, segui com leituras filosóficas e até escrevi uns poucos artigos que enviei ao Dr. W. T. Harris, o famoso hegeliano e editor do Journal of Speculative Philosophy, o único periódico de Filosofia no país àquela época, assim como ele e seu grupo constituíam quase que o único grupo de laicos dedicados à Filosofia por motivos não-teológicos. Ao enviar um artigo, eu pedi ao Dr. Harris um conselho sobre a possibilidade de obter sucesso prosseguindo nos estudos filosóficos. Seu retorno foi tão encorajador que foi um fator preeminente na minha decisão de tentar a Filosofia como carreira profissional.

Os artigos enviados eram, como deles eu me recordo, altamente esquemáticos e formais; eram pautados em linguagem do intuicionismo; eu era, então, ignorante de Hegel.

Apenas nessa oportunidade Dewey se refere a William Harris (1835$1909)^{9}$. Embora não tenha sido seu professor stricto sensu, Harris esteve direta

9 “Em 1866, depois da Guerra Civil [William Torrey Harris e Henry C. Brokmeyer] deram início à St. Louis Philosophical Society, a mais importante tentativa a Oeste de especulação filosó- 
ou indiretamente presente na carreira de Dewey quer como filósofo quer como pensador da educação; não fosse por outra razão, Harris, como dito acima, era editor do primeiro e, por muito tempo, o mais importante periódico norte-americano de Filosofia, assim como foi tradutor de obras de Hegel - destacadamente a Lógica à qual se dedicou por quase meio século.

Para muitos dos contemporâneos de John Dewey, era dispensável a intermediação de compatriotas para o acesso das diferentes vertentes do pensamento europeu, soe dizer alemão, em primeiro lugar, e francês, em segundo. Tanto o alemão quanto o francês eram falados e lidos com fluência pela elite intelectual norte-americana, até ao menos as primeiras décadas do séc. XX. A difusão do alemão entre as elites dos Estados Unidos se deveu, de um lado, às ondas imigratórias dos anos de 1840 que levou para os Estados Unidos uma parcela considerável da intelectualidade liberal alemã ${ }^{10}$; de outro, até a Primeira Guerra Mundial, muitas centenas de jovens norte-americanos realizaram viagens de estudos para a Alemanha, seja para estágios nos modernos laboratórios de pesquisa, seja para completar os estudos de graduação e pós-graduação (MARSDEN, 1994).

Dewey foi um dos poucos intelectuais de sua época a realizar todo o seu ciclo de formação nos Estados Unidos. Por isso mesmo, a convivência e o estudo com acadêmicos vindos de estudos na Europa/Alemanha - tais como: George S. Morris, William James e G. Stanley Hall - lhe foram decisivos para o exame das correntes modernas do pensamento filosófico. Nesse contexto, o papel do proeminente hegeliano, editor e tradutor de Hegel se destaca para a geração de intelectuais norte-americanos que se formou na segunda metade do séc. XIX e para John Dewey em particular ${ }^{11}$.

Como afirma Kuklick (1985, p. 178), as muitas comunidades alemãs que se criaram nos Estados Unidos contribuíram para a conexão entre as sociedades especulativas. "Os hegelianos de St. Louis eram apenas primus inter pares entre os filósofos do [lado] Oeste [dos Estados Unidos]". Primeiros, também, no modo como operavam com Hegel como instrumento para enfrentar as candentes

fica (em contraste com a teológica). Harris, Brokmeyer e seus associados se tornaram famosos nos círculos intelectuais como os Hegelianos de St. Louis" (KUKLICK, 1985, p. 177).

${ }^{10}$ Esse é o caso do hegeliamo Henry C. Brokmeyer (1826-1906) que fugiu da Alemanha para os Estados Unidos em 1844.

${ }^{11}$ Acrescente-se, ainda, a mais próxima convivência de William Harris e John Dewey a partir do momento em que se encontraram também no campo educacional, ambos partícipes dos debates em torno das reformas educacionais, profundamente envolvidos em densas discussões escolares e pedagógicas: o primeiro como administrador das escolas públicas de St. Louis (1868-1880) e Comissário Geral da Educação dos Estados Unidos (1889-1906), e o segundo como professor universitário e fundador da Laboratory School at University of Chicago (1894). 
questões políticas - como o fez Brokmeyer que acabou por assumir o governo de Missouri entre 1875-1880 - ou como pressuposto indispensável para entender a Psicologia - como o fez Harris ao longo do tempo.

Foi porque Harris e seus seguidores pensaram que na filosofia hegeliana era preciso ver a espada com a qual abater o monstro de três cabeças da monarquia na política, o tradicionalismo na religião e o naturalismo na ciência, que se animaram a levar a cabo e tiveram a perseverança para empreender a obra de nacionalizar o hegelianismo nos Estados Unidos (MUIRHEAD, 1928, p. 239).

Para Jay (2002), William Harris teria sido o primeiro verdadeiro mentor de John Dewey ${ }^{12}$.

Em 1882, Dewey deu início a dois anos de estudos na Johns Hopkins University, com George S. Morris, realizando todos os cursos por ele oferecidos. Em 1884, obteve o título de Doctor of Philosophy com uma tese sobre Kant. A Morris são destinadas as palavras mais elogiosas e agradecidas de Dewey. Sobre as marcas deixadas pelo mestre, diz em From Absolutism...:

Nunca conheci um homem tão sincero e generoso - um homem singular/ único, [durante todo o período em estivemos juntos, MJW]; enquanto eu, que desde há muito afastara de sua orientação filosófica, deveria estar feliz por acreditar que a influência do espírito de seu ensino tem sido uma influência duradoura (DEWEY, 1930, p. 152).

George Sylvester Morris (1840-1889) era também originário de Vermont, de uma família de abolicionistas. Estudou no College de Dartmouth; durante a Guerra Civil, interrompeu os estudos para servir no Regimento de Vermont; encerrado o conflito, matriculou-se no Union Theological Seminary da cidade de Nova York, onde decidiu ler Hume que lhe provocou uma devastadora crise de fé. Em seguida (1866), decide ir para Berlin estudar, por dois anos, com o filósofo Friedrich Adolf Trendelenburg (1802-1872), opositor do hegelianismo ${ }^{13}$.

${ }^{12}$ Sobre William T. Harris e outros hegelianos norte-americanos que se destacaram a partir de fins da Guerra Civil há um artigo de Warde, no prelo.

${ }^{13}$ Por coincidência, William James estava em visita a Berlin na mesma época. 
No retorno, suas dúvidas religiosas afastaram pessoas próximas, bem como suas chances de lecionar Filosofia. Por um tempo, foi tutor de um filho de banqueiro de Nova York e somente em 1870 conseguiu uma vaga de professor de Línguas Modernas e Literatura na Universidade de Michigan. Em 1877, começou a lecionar na Johns Hopkins em período parcial, enquanto continuava em Michigan ${ }^{14}$.

Firmemente afastado do empirismo, Morris começou a ler, em 1880, o hegeliano inglês Thomas Hill Green ${ }^{15}$. Quando John Dewey se apresentou para seus estudos em 1882, Morris já era um maduro hegeliano. Para Menand (2001), Morris usava Hegel exatamente como Marsh o teria usado: para conciliar razão e fé. Para que os atributos do Absoluto a que Hegel chegou trabalhando filosoficamente coincidissem perfeitamente com os atributos de Deus da revelação cristã.

Religião como conhecimento pressuposto e requerido do Absoluto, e Filosofia, como sua pesquisa imparcial, pura, e sua demonstração ocupa o mesmo campo [...] "Razão humana" não é confundida pelo conteúdo da consciência cristã, mas é fortalecida, iluminada, satisfeita, em verdade, completada por ela (MENAND, 2001, p. 265).

Essa afirmação ecoaria, portanto, a afirmação de Marsh na introdução a Coleridge: "A fé cristã é a perfeição da razão humana". Assim como concepção orgânica de educação de Morris também ecoaria a concepção de Marsh. Para Morris, nenhuma matéria [tema] pode ser buscada "a menos que tal busca seja acompanhada por um apropriado conhecimento do todo, do qual, corretamente concebido, é um membro vivo, orgânico" (MENAND, 2001, p. 265).

${ }^{14}$ Foi William James que recomendou Morris ao então presidente da John Hopkins, Daniel Gilman, declinando do convite endereçado a ele. Na carta de 1789, em que trata do assunto, James recomendou G. Morris como excelente professor para história da filosofia, e na linha mais psicológica disse não conhecer outros além de C. Peirce e S. Hall. Diante de tão balizadas indicações, contratou probatoriamente os três em tempo parcial até que tivesse segurança para investir em um deles em caráter permanente. Dewey foi aluno também de Peirce e Hall.

${ }^{15}$ Thomas Hill Green (1836-1882), segundo a Stanford Encyclopedia of Philosophy, era filósofo político e radical, reformista moderado, e líder do movimento do idealismo britânico. Foi professor de Filosofia Moral no Balliol College de Oxford. Seus prinicipais ensaios são, dentre muitos outros: Essay on Christian Dogma, The Conversion of Paul, Different Senses of "Freedom" as Applied to Will and the Moral Progress of Man, Faith, Lecture on Liberal Legislation and Freedom of Contract. Green foi discípulo de Benjamin Jowett que introduziu pela primeira vez os escritos de Hegel na Inglaterra. Green se tornou hegeliano destacadamente pelo apelo político e igualitarista que encontrou nos escritos de Hegel. 
O hegelianismo de Morris não era contemplativo; fez de seu cristianismo uma religião de engajamento - uma vez que em Hegel o Absoluto é realizado não no pensamento, mas no desenrolar da História. Dessa perspectiva, autorrealização é um processo social. Sobre isso, Marsh teria dito anteriormente:

A vitória do cristianismo não é conseguida através de uma tentativa extraída do mundo, mas pela sua superação; pela persistência no mundo e sua conquista. $\mathrm{O}$ "self universal" do homem não é uma abstração, mas, como todos os universais verdadeiros, um poder de realizar-se em e através dos materiais de oportunidades e circunstâncias particulares, no meio do qual o indivíduo pode ser colocado (MARSH apud MENAND, 2001, p. 265).

Morris e Dewey cedo se identificaram; partilharam o ódio pelo empirismo. E com Hegel, Dewey encontrou o que buscava: a Filosofia como guia para viver. A Filosofia de Hegel fez um mais próximo corolário da imagem do corpo como o organismo integrado de Huxley do que o kantismo atenuado de Torrey havia feito.

Sobre o lugar ocupado por Morris no quadro filosófico da época, diz Dewey (1930, p. 152-153) em From Absolutism...

Ele chegou a Kant através de Hegel ao invés de chegar a Hegel pelo caminho de Kant, assim, sua posição em relação a Kant era aquela expressa pelo próprio Hegel. Além disso, ele reteve de sua formação inicial na filosofia escocesa algo da crença do senso comum na existência do mundo externo. Ele usava para se divertir daqueles que pensavam que a existência do mundo e da matéria eram coisas a serem provadas pela Filosofia. Para ele, a única questão filosófica era o significado dessa existência; seu idealismo era inteiramente do tipo objetivo. Como o seu contemporâneo, Professor John Watson, do Kingston, ele combinava a metafísica idealista e lógica com a epistemologia realista. Através do seu professor em Berlim, Trendelenburg, ele havia adquirido grande respeito por Aristóteles, e não tinha dificuldade em unir aristotelismo com hegelianismo.

Afirmando a união entre aristotelismo e hegelianismo, operada por Morris, Dewey curiosamente o identifica com William Harris para quem 
Hegel está mais próximo da Metafísica de Aristóteles - livro onze - do que de qualquer outra obra. E cremos estar certos quando afirmamos isso, porque Hegel mesmo nos deu a conhecer a opinião de que sua filosofia é uma filosofia do pensamento puro no sentido em que Aristóteles concebe o nous... Em 1863 comecei a me ocupar com a História da Filosofia de Hegel, e desde aquele tempo adquiriram tal clareza as obras de Platão e Aristóteles que, desde então, não tem deixado de crescer, em cada década que passa, a sua compreensão. O mais maravilhoso das passagens da Metafísica de Aristóteles... Hegel o escolheu para figurar como sentença final de sua Enciclopédia das Ciências Filosóficas... Aristóteles demonstra que o Absoluto deve ser concebido como ato puro, e como semovente. E sua grande intuição é que a atividade e seu objeto são uma mesma coisa. "O pensamento e o ser são uma e a mesma coisa" não é uma sentença hegeliana, mas uma sentença tão velha, ao menos, quanto a filosofia aristotélica. A atividade da intuição especulativa produz aquilo que percebe (HARRIS, 1909, apud SCHNEIDER, 1950, p. 440).

Quanto ao lugar ocupado pelo hegelianismo em sua formação, Dewey afirma em From Absolutism...:

[...] preencheu uma demanda por unificação que era indubitavelmente uma ânsia emocional intensa, e era mesmo um apetite que somente um tema de estudo intelectualizado poderia saciar. É mais do que difícil, é impossível, reconstituir aquela disposição inicial. Mas o sentido de divisões e separações que, eu suponho, estavam nascendo dentro de mim como uma conseqüência da herança da cultura da Nova Inglaterra, divisões decorrentes do isolamento do self em relação ao mundo, da alma em relação ao corpo, da natureza em relação a Deus, provocaram uma dolorosa opressão - ou melhor, elas eram uma íntima laceração. Meu estudo filosófico inicial tinha sido uma ginástica intelectual. A síntese do sujeito e do objeto de Hegel, matéria e espírito, do divino e do humano, não era, de que modo, mera fórmula intelectual; operava como uma descompressão, uma liberação. O tratamento de Hegel da cultura humana, das instituições e das artes envolvia a mesma dissolução de inflexíveis divisões de paredes, e [por isso] exerceu em mim uma especial atração (DEWEY, 1930, p. 153).

Apesar das considerações respeitosas e agradecidas a Morris, Dewey prossegue em From Absolutism... relativizando quer o peso de Morris na sua introdução ao sistema hegeliano quer a duração da ascendência filosófica do mestre sobre ele. 
Embora fosse impossível que um estudante jovem e impressionável, ignorante de qualquer sistema de pensamento que pudesse satisfazer sua cabeça e coração, não tivesse sido profundamente influenciado, a ponto de, ao menos, uma temporária conversão pela devoção acadêmica e entusiasta de Mr. Morris, o efeito estava longe de ser a única fonte do meu próprio "hegelianismo". Os anos oitenta e noventa eram uma época de fermento novo no pensamento inglês; a reação contra o individualismo atomístico e o empirismo sensorialista estava em pleno vapor. Era a época de Thomas Hill Green, dos dois Caird, de Wallace, do aparecimento dos Essays in Philosophical Criticism, produzido em cooperação por um grupo de mais jovens sob a liderança do idoso Lord Haldane (DEWEY, 1930, p. 152) ${ }^{16}$.

Ainda que expresse, ao término do texto, a sensação de que Hegel tenha lhe deixado "um sedimento permanente em seu pensamento", é certo que os escritos de Dewey da década de 1890 indicam o seu afastamento crescente quer da lógica quer da epistemologia hegeliana. Da história hegeliana sobraram resquícios do sentido de superação, porém fundidos com a ideia de evolução natural. $\mathrm{O}$ fato de ter se afastado de Hegel - o que implica necessariamente ter se afastado filosoficamente de Morris - não justifica, todavia, o silêncio de Dewey sobre James Marsh e William Harris em relação a George S. Morris. Ou seja, Dewey apaga ambos quer em si quer em Morris.

Dewey escreveu From Absolutism... em sua maturidade. Àquela altura as intricadas relações entre as vertentes de pensamento pelas quais passara já teriam se esclarecido ou, na pior das hipóteses, teria se utilizado da sua mais antiga ferramenta de apagamento ou de negação daqueles que em algum momento e

${ }^{16}$ No trecho citado, Dewey se refere a Green, já citado anteriormente, aos dois Cairds e a Wallace. Os Cairds referidos são os irmãos escoceses: John Caird (1820-1898), téologo presbiteriano, foi professor de Teologia na Universidade de Glasgow; escreveu, dentre outros, Introduction to the Philosophy of Religion (1880), e Edward Caird (1835-1908), professor de Filosofia da Universidade de Glasgow, a partir de 1866, foi uma das figuras centrais no movimento idealista britânico que dominou a filosofia na Grã-Bretanha entre 1870 e os anos de 1920. E. Caird, que se tornou famoso pelos estudos e escritos sobre Kant e Hegel, exerceu profunda influência sobre a chamada "segunda geração" de idealistas, tais como John Watson e Bernard Bosanquet, ambos estudados por J. Dewey. E. Caird durante toda a vida se envolveu ativamente nas questões da universidade, da política local bem como das reformas sociais e educacionais. Sua maior obra é $A$ Critical Account of the Philosophy of Kant (1877). Quanto a Wallace, é provável que Dewey se refira a William Wallace (1844-1897), sucessor de T. Green na cadeira de Filosofia Moral, de Oxford, com o qual guardava grande afinidade de pensamento. Wallace dedicou mais do que todos os seus colegas a elucidar o pensamento de Hegel. Dentre suas principais obras constam: Hegel's Philosophy of Mind (1898) e Lectures and Essays on Natural Theology and Ethics, além da tradução da Logic de Hegel (1873). 
de algum modo haviam exercido ascendência sobre ele. Nesse sentido, vale destacar a ausência, ainda, de G. Stanley Hall (1844-1924), cujos seminários foram seguidos por Dewey à época da sua formação Johns Hopkins. Com Hall, Dewey adentrou no terreno dos experimentos que estavam constituindo as bases do que se consagrou nos Estados Unidos, em fins do séc. XIX, como "Nova Psicologia" para distingui-la da Psicologia como um ramo ou tópico da Filosofia; além de ter sido apresentado por Hall à Psicologia experimental e teórica de Wilhelm Wundt (1832-1920), um dos maiores nomes das novas concepções biológicas da Psicologia.

Ausente está também William James (1842-1910), cujo Principles of Psychology de 1890 deu uma nova e definitiva direção às incursões psicológicas de Dewey (RECK, 1984). Sobre a presença de James na formação deweyana, consta da biografia preparada pela filha de Dewey (DEWEY, J., 1939, p. 23):

A influência de James sobre a teoria do conhecimento de Dewey foi exercida não pelo Pragmatism, que apareceu depois da teoria de Dewey estar formada, mas pelos capítulos do Principles of Psychology que tratam de concepção discriminação, comparação e raciocínio.

E completa:

Principles of Psychology de William James é de longe a maior influência individual na mudança de direção do pensamento filosófico de Dewey.

Entre as fontes de John Dewey, é indispensável ainda mencionar George H. Mead (1863-1931), de quem foi colega em Michigan entre 1891 e 1904, e para sempre amigo pessoal e familiar. A Psicologia da origem e natureza do self desenvolvida por Mead que, deslocando o fundamento psicológico do âmbito natural para o social, ou seja, para as relações dos homens entre si, provocara mais uma guinada filosófica de Dewey rumo aos temas sociais. Sobre o papel exercido por Mead na trajetória de Dewey, diz Jane Dewey, que as ideias a respeito do self não teriam sido desenvolvidas pelo pai, uma vez que ele "as tomou de Mead e fez delas parte de sua subseqüente filosofia; sendo assim, dos anos noventa em diante, a influência de Mead teria pareado àquela de James" (DEWEY, 1939, p. 26).

É certo que este artigo deixou de fora algumas outras fontes fundamentais ao pensamento de John Dewey; dentre as excluídas, a mais importante é a teoria 
evolucionista de Charles Darwin que merece, ao lado dos três últimos nomes citados, um tratamento especial, o que será feito em outro artigo.

\section{À guisa de conclusão}

John Dewey (1930, p. 155) diz sentir inveja daquelas pessoas capazes de escrever uma autobiografia intelectual em um padrão unificado, no qual aparecem poucos e claros "interesses e influências". Ele, pelo contrário, parece ser instável, camaleônico, rendendo-se a muitas e sucessivas influências, até mesmo as incompatíveis, lutando por assimilar algo de cada uma e esforçando-se por levá-las adiante de um modo "logicamente consistente" (DEWEY, 1930, p. 155).

Curiosamente, não é essa imagem que se extrai de sua coerente trajetória, que aparenta certa linearidade. John Dewey envereda com desenvoltura por vários caminhos teóricos, mas parece portar uma ferramenta precisa de extração daquilo que lhe é intelectualmente útil e de subsequente dispensa da fonte de que se nutriu.

Nessa direção, aponta Jay (2002, p. 52-53) em sua biografia de Dewey sobre o biografado: que estaria sempre à frente dos seus professores; adotava um mentor, absorvia suas ideias, e então tentava superá-lo. Essa solução, que ele teria aprendido com o pai, trazia benefícios, uma vez que nunca Dewey seria discípulo de alguém por muito tempo, mas, por outro lado, provocava o efeito danoso de sempre empurrá-lo para soluções negativas, ou de colocá-lo contra os seus mentores que em algum momento o teriam apoiado, por período mais ou menos longo.

\section{REFERÊNCIAS}

COUGHLAN, Neil. Young John Dewey. Chicago: University of Chicago Press, 1975.

DEWEY, Jane M. Biography of John Dewey. In: SCHILPP, Paul A.; HAHN, Lewis E. (Eds.). The Philosophy of John Dewey. Chicago: Northwestern University, 1939. p. 3-45.

DEWEY, John. The Philosophical Work of Herbert Spencer. In: The Collected Works of John Dewey. The Middle Works of John Dewey, 1899-1924. Volume 3: 19031906, Essays. The Eletronic Edition, 1904. [MW.3]. 
. From Absolutism to Experimentalism. In: . The Collected Works of

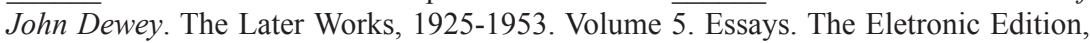
1930. [LW.5].

. James Marsh and American Philosophy. In: . The Collected Works of John Dewey. The Later Works, 1925-1953. Volume 5. Essays. The Eletronic Edition, 1941. [LW.5].

DYKHUIZEN, George. The Life and Mind of John Dewey. Carbondale: Southern Illinois University Press, 1973.

JAY, Martin. The Education of John Dewey. A Biography. New York: Columbia. Univ. Press, 2002.

KUKLICK, Bruce R. Churchmen and Philosophers: from Jonathan Edwards to John Dewey. New Haven: Yale Univ. Press, 1985.

. The rise of American philosophy: Cambridge, Massachusetts, 1860-1930. New Haven, London: Yale Univ. Press, 1977.

MARSDEN, George M. Religion and American culture. San Diego: Harcourt Brace Jovanovich, 1990.

. The evangelical mind and the New School Presbyterian experience: a case study of thought and theology in nineteenth-century America. New Haven: London: Yale University Press, 1970.

. The Soul of the American University. From Protestant Establishment to Established Nonbelief. New York: Oxford Univ. Press, 1994.

MARSDEN, George M.; LONGFIELD, Bradley. The Secularization of Academy. New York: Oxford University. Press, 1992.

MENAND, Louis. The Methaphysical Club. New York: Farrar, Straus \& Giroux, 2001. MUIRHEAD, J. H. How Hegel Came to America. The Philosophical Review, v. 37, n. 3, p. 226-240, 1928.

RECK, Andrew J. The Influence of William James on John Dewey in Psychology. Transactions, v. 20, n. 2, p. 87-117, 1984.

SCHNEIDER, Herbert W. Historia de la filosofia norteamericana. Mexico: Fondo de Cultura Económica, 1950.

Texto recebido em 22 de junho de 2012.

Texto aprovado em 23 de abril de 2013. 